Original Article

\title{
PREPARATION, CHARACTERIZATION AND STUDIES OF PHYSICOCHEMICAL AND BIOLOGICAL PROPERTIES OF DRUGS COATING LACTOSE IN FLUIDIZED BEDS
}

\author{
E. V. USPENSKAYA*, T. V. PLETENEVA, A. V. SYROESHKIN, I. V. TARABRINA
}

Department of Pharmaceutical and Toxicological Chemistry, Peoples Friendship University of Russia (RUDN University), 6, MiklukhoMaklaya st, Moscow, 117198, Russian Federation

Email: uspenskaya75@mail.ru

Received: 13 May 2020, Revised and Accepted: 30 Jun 2020

\begin{abstract}
Objective: Study physicochemical properties and activity of biotechnological drugs coating lactose particles in fluidized beds for the development of a prospective approach of their identification.

Methods: Lactose monohydrate as pharmaceutical excipient; affinity-purified polyclonal rabbit antibodies to recombinant human interferongamma as a drug substance; Pilotlab fluid bed apparatus was used for lactose powder saturation with solutions of pharmaceutical substances to the point of granulation (pelletizing); inverse light scattering method (2D-LS) for analysis of micron vibrations frequency spectra of samples surfaces for light intensity distribution in time by values of $\mathrm{d} 1, \mathrm{~d} 2, \mathrm{~d} 3$ primary descriptors; low angel and dynamic laser light scattering (LALLS, DLS) methods for distribution of lactose-water (LW) supramolecular complexes into volume fractions (micron "size spectra"), using the Master Sizer 2000 instrument and Zeta Sizer Nano ZS instrument in the nanoscale; Spirotox method for research of biological activity to determine the activation energy $\left(\mathrm{E}_{\mathrm{a}}\right)$ values of cell death in solutions of tested samples.

Results: Changes in 2D-LS scattering time on sample surfaces, described by topological descriptors, made it possible to clearly differentiate the intact lactose from fluidized samples by specific corridors in coordinates $d_{i}=F(t)$. The calculated activation energy ( $\left.E_{a}\right)$ values of cell biosensor death process in solutions of drugs coating lactose allow to characterize the biological activity of it in the initial (by Ea increase) and activated state (by E decrease) after the creation of intra-laboratory transmucosal conditions. A unique dimensional spectrum of LW-complexes in the nanoscale range was obtained by DLS. The differences between samples in the distribution of LW complexes in the size range from $1 \mu \mathrm{m}$ to $125 \mu \mathrm{m}$ was showed by
\end{abstract} LALLS.

Conclusion: The developed approach, including Chemometrics, laser and biotesting methods can be used for qualitative the analysis tasks as well as for analytical control of the fluidization process in cases where identifiable pharmaceutical substances are not distinguishable by traditional analytical methods.

Keywords: Lactose, Antibody, Microfluidics, Supramolecular complexes, Spirotox, Light scattering, Thermal activation

(C) 2020 The Authors. Published by Innovare Academic Sciences Pvt Ltd. This is an open access article under the CC BY license (http://creativecommons.org/licenses/by/4.0/) DOI: http://dx.doi.org/10.22159/ijap.2020v12i5.38281. Journal homepage: https://innovareacademics.in/journals/index.php/ijap

\section{INTRODUCTION}

In the epoch of a sharp rise in industrial volumes of drug production, the process of "homogeneity" of its creation with necessary functional characteristics acquires special importance $[1,2]$. The pharmaceutical and technological aspect of the quality of coating of solid dosage forms is of great importance, which is the final operation in the drug production. The quality and marketability of pharmaceutical products, decomposition, dissolution as well as modeled active pharmaceutical ingredient (API) release and achievement of maximum therapeutic efficiency depend on the way it is organized. At modern pharmaceutical manufactures for application of coatings on firm medical products (powders, pills, dragee) fluidized bed (FB) devices were used, which work is based on laws of hydrodynamics and heat exchange in dispersed mediums [3-5].

Fluidization consists in the rapid formation of isolated droplets of a drug substance in the transport flow of liquids - a type of reaction micro-cameras [6]. Droplet formation begins the penetration of the dispersed phase into the channel with a continuum phase. There are forces influencing the droplet formation at the interface. Balance and correlation of these forces determine the processes of interaction of two flows [7, 8]. Examples of hydrodynamic forces are the wall repulsion force ( $\mathrm{F}$ wall) originating from the asymmetry of the vorticity around the particles, pushing the particles away from the wall, and the shear-gradient lift force (F shear) originating from the curvature of the shear flow profile, which leads the particles to migrate away from the central axis [9]. Due to the competition between these two forces, particles suspended in the fluid migrate across streamlines when flowing downstream, and finally equilibrate at a specific location in the channel's cross-section (fig. 1).

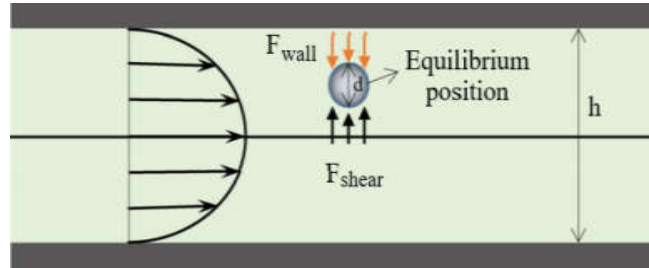

Fig. 1: Schematic illustration of the forces on a suspended particle and the equilibrium position of the particle in a fully developed flow in a confined channel [10]

One of the main parameters determining the properties of fluid systems is the Randol's Number at $\mathrm{Re}<2000$-the laminar and mass transfer flow is determined by diffusion. Such conditions allow effective mixing of liquid flows [11].

Reducing the transverse channel accelerates mixing and controls the flow of liquids in space and time. The activation of solid and liquid systems leads to changes in their physical and chemical properties, reactivity and other properties. Analytical systems implementing the described technological capabilities were named "microfluidics, nanofluidics and lab-on-a-chip science and technology" [12]. The concept of compartmentalization of chemical reactions (reactions 
that take place in small, isolated volumes) is effectively applied in pharmaceutical production to create innovative drugs of directional and modified action [13]. Therapeutically, innovative drugs provide an advantage over existing methods of treatment in the case, fo example, of relatively low doses when the desired effect is achieved, or when a drug contains substances of biotechnological originantibodies to specific antigen targets [14]. In recent years antibody preparations have found wide application in medicine due to targeting of pathophysiological causes of infectious, autoimmune, oncological and other socially significant diseases [15-18]. Taking into account the current world situation with regard to the rapid spread of respiratory infection, the development of new drugs aimed at targets important for virus reproduction as well as specific methods of quality control is relevant $[19,20]$

The purpose of the present work is to study the physical-chemical properties and activity of biotechnological drugs based on lactose diluent in comparison with placebo obtained under conditions of fluidization in order to develop a perspective method of quality control by "identification" parameter.

\section{MATERIALS AND METHODS}

In this work, Lactose monohydrate (SuperTabR30GR) is presented in a variety of forms, including excipient, tablet diluent, capsules, powders (DMV-Fonterra Excipients $\mathrm{GmbH}$ and Co. KG, Norten Hardenberg, Germany) (fig. 2) [21]. Diluents are used to ensure the necessary mass of the tablet if the composition contains a small amount of active substances [22, 23].

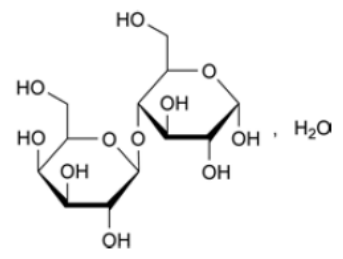

$O$ - $\beta$-D-Galaktopyranosyl-(1 $\rightarrow 4)$ - $\alpha$-D-glucopyranose monohydrate Fig. 2: Structural for monohydrate lactose

\section{Fluidized bed granulation}

The following process of granulation in a fluidized bed consisted of mixing lactose powder in a suspended layer with subsequent moistening with water-alcohol solutions of medicinal substances while the mixing continued. Pelletizing centers in fine powder are granulation liquid droplets or dispersed particles containing active centers with excessive energy (fig. 3) [27, 28].

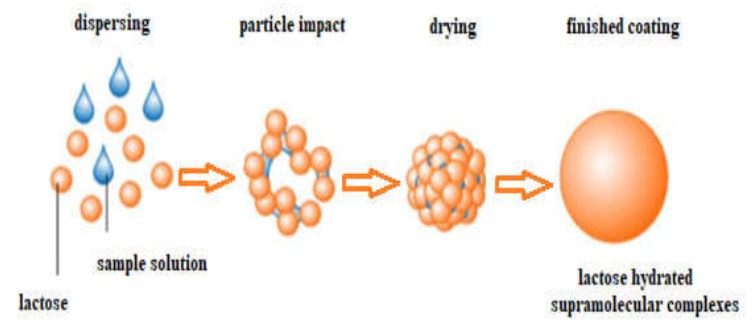

Fig. 3: Direct granulation process [29]

\section{Drugs preparation}

Affinity-purified polyclonal rabbit antibodies (Abs) to recombinant human interferon-gamma (IFNg) were manufactured by Angel Biotechnology Holdings plc (Edinburgh, UK). Buffer solution of antibodies to IFNg $(2.5 \mathrm{mg} / \mathrm{ml})$ was mixed with a solvent (ethanolwater solution) by using a microfluid analytical system with $1000 \mu \mathrm{l}$ flow chip-microreactor (Syrris Ltd, UK) to produce dilutions according to the technology described in the US patent 8535664 (31) [24]. In the case of the placebo, the solvent was used to prepare samples of the buffer instead of Abs to IFNg following the method described above (a buffer solution which is equivalent to the vehicle for Abs to IFNg [25]. Lactose monohydrate powder was saturated with solution Abs to IFNg and placebo on a Pilotlab fluid bed apparatus (Hüttlin GmbH, Schopfheim, Germany) to the point of granulation (pelletizing) [26].

\section{Methods of research}

\section{Spirotox method}

Research of biological drug activity was carried out with the use of test culture Spirostomum ambiguum, characterized by statistically reliable sensitivity to toxicants $[30,31]$. The kinetic scheme of ligand-induced death of $S$. ambiguum includes the interaction state $\left(\mathrm{C}_{\text {cell }}{ }_{n} \mathrm{~L}\right)$, the intermediate state $\left(\mathrm{C}-\mathrm{L}_{\mathrm{n}}\right)$ and the state of transition to the cell dead (DC), determining the ligand-receptor interaction rate (fig. 4)

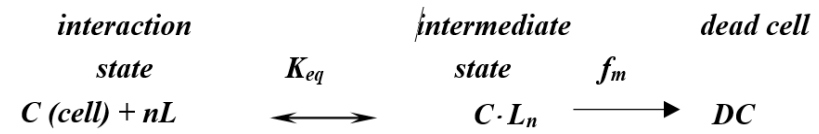

Fig. 4: Kinetic scheme of ligand-receptor interaction $S$. ambiguum with toxicant

The dependence of lifetime on temperature is linearized in "Arrenius coordinates" [32, 33]:

$$
\mathrm{k}=\mathrm{A} \cdot \mathrm{e}^{-\mathrm{E}_{\mathrm{a}} / \mathrm{RT}} \text {. }
$$

\section{D-LS-method}

The analysis of occurrence frequency spectra of micron vibrations of the sample's surface was carried out by 2D-LS inverse dynamic light scattering method using the developed installation and original software, based on the definition of topological descriptors dependences on time [34]. For the analysis of lowfrequency micro oscillations of drugs, a portable optical microscope was used and was connected to a personal computer USB-camera. The obtained interference patterns were mathematically processed with the help of three descriptors (criteria of difference), which reflect their degree of difference and allow estimating them quantitatively Vidan ${ }$ software was used for data processing $[35,36]$

Laser scattering methods were used to characterize the supramolecular dispersion of samples by the distribution of clusters into volume fractions ("size spectra"), using the Master Sizer 2000 instrument and Zeta Sizer Nano ZS instrument (MALVERN Instruments, UK) [37]

Temperature activation of the powders under study was carried out using a solid-state thermostat for $15 \mathrm{~min}$ at $37^{\circ} \mathrm{C}[38,39]$

\section{Statistics}

The findings were processed by the statistical methods using software packages of Origin Pro 9.1. Each value on the fig. represents "mean $\pm S D$ ", significant differences were considered when $\mathrm{p}<0.05$

\section{RESULTS}

The process of preparation of drug solutions by fluidization method is accompanied by the following physical and chemical processes: addition of solvent portions, a decrease of initial substance content, hydrodynamic processes connected with mixing, the interaction of components with each other and with capillary tube's surface, the appearance of new active centers, energy changes [40-42]. As a result, the properties of the complex system "solvent active pharmaceutical ingredient" change and differ from the original substance [43-45]. 


\section{D-LS method}

The surface of pharmaceutical substances is a unique characteristic and its properties depend on the chemical nature of the analyzed object and the peculiarities of synthesis. The results of the 2D distribution of scattered light intensity in time by values $\mathrm{d}_{1}, \mathrm{~d}_{2}, \mathrm{~d}_{3}$ of primary descriptors reflecting micron vibrations on the surface are presented in fig. 5 .

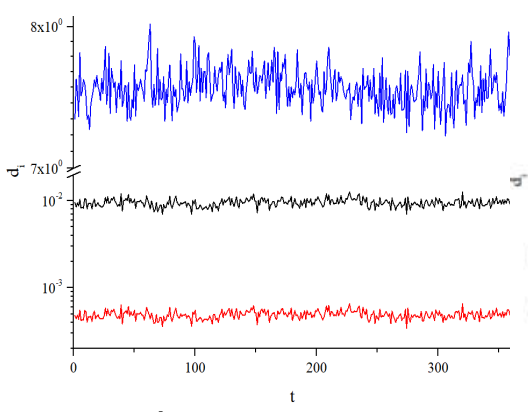

A

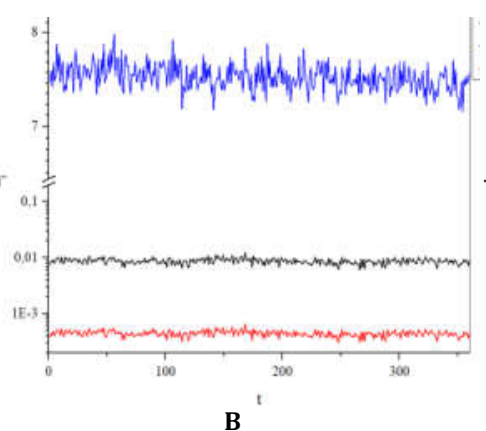

B

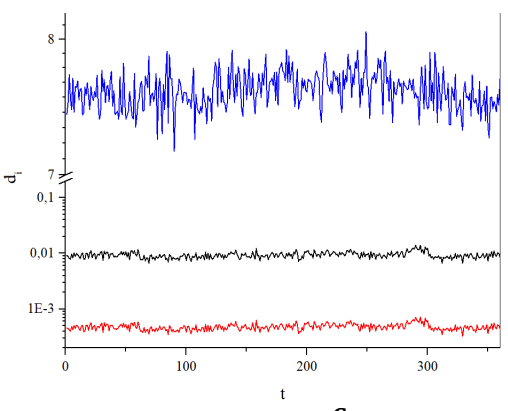

C

Fig. 5: Evaluation of the $2 D$ light scattering patterns (LS) of drugs coating lactose as functions $d_{i}=F(t)$. A-Intact lactose (lactose monohydrate SuperTabR30GR); B-FB placebo drug (lactose with buffer solution); C-FB drug (lactose with solution Abs to IFNg) ( $\geq 50$, p<0.05)

Changes in 2D light scattering time of specimen surfaces described with topological descriptors $\mathrm{d}_{\mathrm{i}}=\mathrm{F}(\mathrm{t})$ made it possible to determine definitely the intact lactose sample (fig. 5A), which hadn't been involved in the process of fluidization as a result of the form individual " corridors" in $\mathrm{d}_{\mathrm{i}}=\mathrm{F}(\mathrm{t})$ coordinates. For differentiation of drugs after lactose coating in the fluidized bed, we used the analysis of the frequency composition of the measured 2D-LS signal based on Fourier transform (fig. 6).

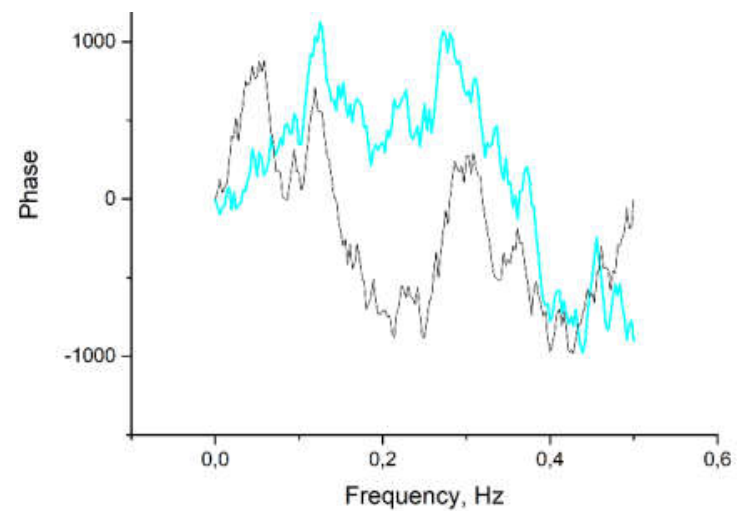

Fig. 6: Fourier transformation of 2D-LS sample measurement results, Black-FB placebo drug (lactose with buffer solution); Blu-FB drug (lactose with solution Abs to IFNg) $(n \geq 50, p<0.05)$

It should be noted that identifying drug substances are chemically indistinguishable, but their spatial structure is the basis for the observed specificity of 2D light scattering.

\section{Spirotox-test}

Recently we have established the dependence of death kinetics of $S$. ambiguum on temperature (fig. 7) [46]. The activation energy ( $\mathrm{E}_{\mathrm{a}}$ ) values of cell biosensor death process in solutions of drugs were assessed.

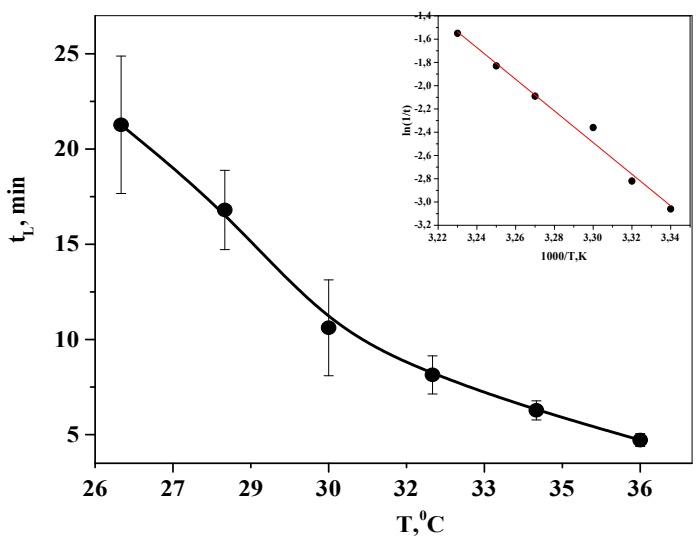

Fig. 7: Dependence of a cellular biosensor lifetime on temperature in $6 \%$ solutions of lactose monohydrate in water $(n=5, p<0.05)$; the graph includes an Arrhenius plot

The existence of the intermediate state (fig. 4) in the process of the test object death means that the death of the cell should take place while activating the process of destruction of the cell with the energy consumption [47]. Indeed, we established the dependence of the kinetics of the death of $S$. ambiguum on temperature. The change of properties was noted by us when comparing the energy values of cell transition activation on the example of lactose of intact, biotechnologically obtained drug (Abs to IFNg) and placebo drug. Based on the physical and chemical interpretation of the activation energy, we can conclude that the higher the values of the apparent activation energy of cell death, the greater the energy barrier to cell death (table 1).

Table 1: Activation energy values of the ligand-induced death of $S$. ambiguum in solutions of different lactose samples (n=5, p<0.05)

\begin{tabular}{lll}
\hline Samples & $\begin{array}{l}\text { Activation energy, } \mathbf{k J} / \mathbf{m o l} \\
\left(\overline{\boldsymbol{E}_{\boldsymbol{a}}} \pm \mathbf{S D}\right)\end{array}$ & $\begin{array}{l}\text { Cell lifetime, } \boldsymbol{\tau}_{\mathrm{L}}, \mathbf{m i n}(\mathbf{6 \%} \mathbf{w a t e r} \text { solutions, } \mathbf{T}=\mathbf{2 9 7} \mathbf{K}) \\
(\overline{\boldsymbol{\tau}} \pm \mathbf{S D})\end{array}$ \\
\hline Intact lactose (lactose monohydrate SuperTabR30GR) & $108 \pm 5$ & $8.74 \pm 0.16$ \\
FB placebo (lactose with buffer solution) & $112 \pm 5$ & $9.38 \pm 0.6$ \\
FB drug (lactose with solution Abs to IFNg) & $139 \pm 5$ & $10.19 \pm 0.12$ \\
\hline
\end{tabular}


The table demonstrates statistically significant differences in the activation energy values of ligand-induced cell death in the solutions of the investigated samples represented by the formed specific supramolecular lactose-water (LW) complexes. According to our data, substances with high biological activity, characterized by low cell survival, correspond to low Ea values, which is consistent with the low values of toxicity for organisms of a higher hierarchical level [48].
We used the static and dynamic laser light scattering methods (DLS, LALLS) to study the size of LW supramolecular complex distribution [49]. Local «inhomogeneities» of the aqueous solution refractive index caused by fluctuations in the concentration of aqueous-lactose complexes lead to light scattering and the determination of their hydrodynamic radius. We have obtained a histogram of particle size distribution-a unique dimensional spectrum of water-lactose complexes in the nanoscale range (table 2).

Table 2: Distribution of lactose-water (LW) supramolecular complexes by size according to DLS method data (n $\geq 15$ p<0.05)

\begin{tabular}{llll}
\hline Drugs coating lactose & Peak & Size, $\mathbf{n m}(\overline{\boldsymbol{d}} \pm \mathbf{S D})$ & Size fraction, $\%$ \\
\hline Intact lactose (lactose monohydrate & 1 & $268 \pm 151$ & 85 \\
SuperTabR30GR) & 2 & $1.05 \pm 0.2$ & 13 \\
& 3 & $4441 \pm 906$ & 2.5 \\
FB placebo (lactose with buffer solution) & 1 & $202 \pm 82$ & 82 \\
& 2 & $1.16 \pm 0,2$ & 12 \\
FB drug (lactose with solution Abs to IFNg) & 1 & $4233 \pm 992$ & 5.4 \\
& 2 & $252 \pm 125$ & 82 \\
& 3 & $1.07 \pm 0.2$ & 6.3 \\
\hline
\end{tabular}

Light scattering by particles less than $1 \mu \mathrm{m}$ diameter does not depend on the nature of the substance.

Using the physical principle of electromagnetic wave scattering from «inhomogeneities» of density, we had measured the angular distribution of the intensity of light as the laser beam was passing through a cell consecutively filled with different lactose samples. It gave us a way to differentiate the drugs under lactose particle coating in FB from each other by static laser light scattering data (fig. 8).

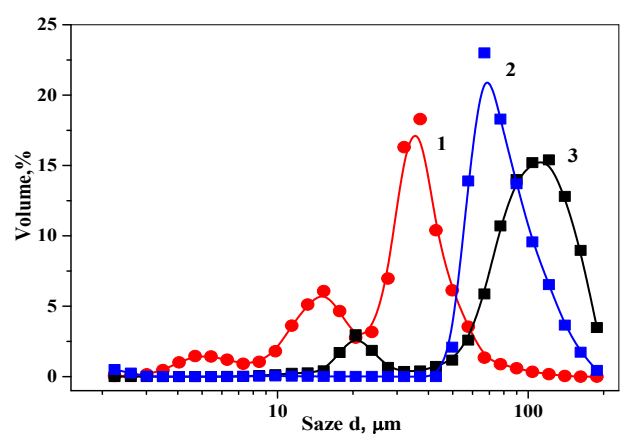

Fig. 8: Distribution of LW supramolecular complexes by size (LALLS method data), 1-Intact lactose; 2-FB placebo; 3-FB drug $(\mathrm{n} \geq 15, \mathrm{p}<0.05)$

Distribution of supramolecular LW complexes by size according to LALLS method in the FB drug solution is represented by the largest size group among comparison samples corresponding to $125 \mu \mathrm{m}$. The smallest size of supramolecular complexes in the sample of intact lactose is $35 \mu \mathrm{m}$ and $15 \mu \mathrm{m}$. Decrease in the scale of heterogeneity that determines the characteristic time of mass transfer of reagents (ligands and cell receptor) to each other contributes to the increase in the reaction rate of their interaction state and reduction of activation energy (table 1).

\section{Structure activation effect of a solid substance}

The study of characteristics of drugs coating lactose obtained by fluidization has shown the need to attract new approaches in quality assessment. To confirm the above described chemometric and laser methods for qualitative analysis and for the analytical control of the fluidization process, we have implemented intra-laboratory methods for the activation of testing samples. For this purpose, FB drug and comparison powders-Intact lactose, FB placebo-were exposed to temperature influence, wetting and gentle grinding with the subsequent investigation of the proposed methods.
The activation conditions of samples have been chosen based on the advantages of transmucosal (buccal and sublingual) delivery: the rate of action associated with high vascularization of mucosal zones, the possibility of reducing the therapeutic dosage, no need to drink water, the absence of destruction outside of gastrointestinal digestive enzymes with efficiency, simplicity and cost-effectiveness of production [50,51] Thus, using a solid-state thermostat, preliminary crushed samples of powders wetted with Mili-Q water were heated to $37^{\circ} \mathrm{C}$ within $15 \mathrm{~min}$.

From the point of view of quantum mechanics representations, the selected conditions are well consistent with the mechanisms of physical and chemical radiation-free relaxation involving a water molecule in the transfer of excitation energy to the surrounding [52].

Fig. 9 shows the results demonstrating a decrease in the energy barrier of the process of cell death in a row: intact lactose (diluent, excipient)-placebo-drug.

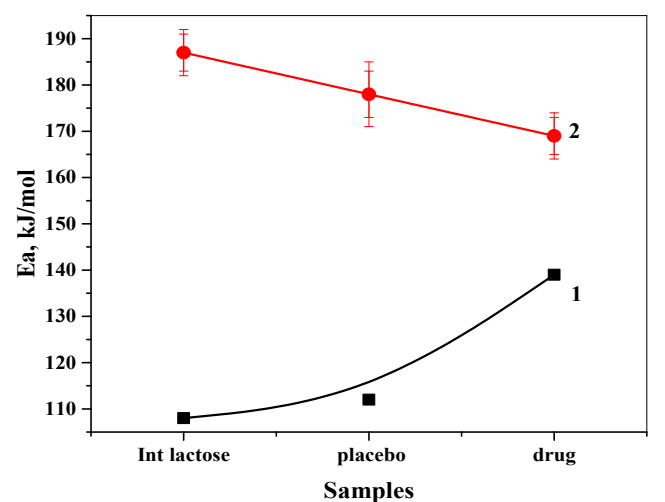

Fig. 9: Energy activation of a cell biosensor death process in 6\% aqueous solutions of drugs coating lactose. 1-normal conditions; 2-conditions of complex influence (temperature, moistened, gentle grinding) $(n=5, p<0.05)$

This can be interpreted as an increase in the biological activity of the tested samples as a result of intra-laboratory effects of temperature, water addition and dispersion (fig. 9).

According to [53], the chemical mechanism of radiation-free relaxation produces final or intermediate products different from the original compounds, which was demonstrated by the distribution of LW supramolecular complexes according to photon correlation spectroscopy (DLS) data (fig. 10). 


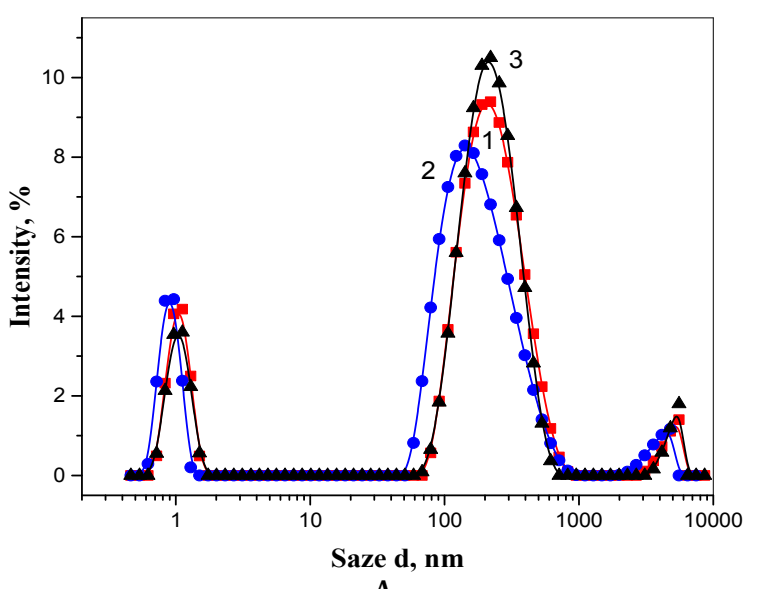

A

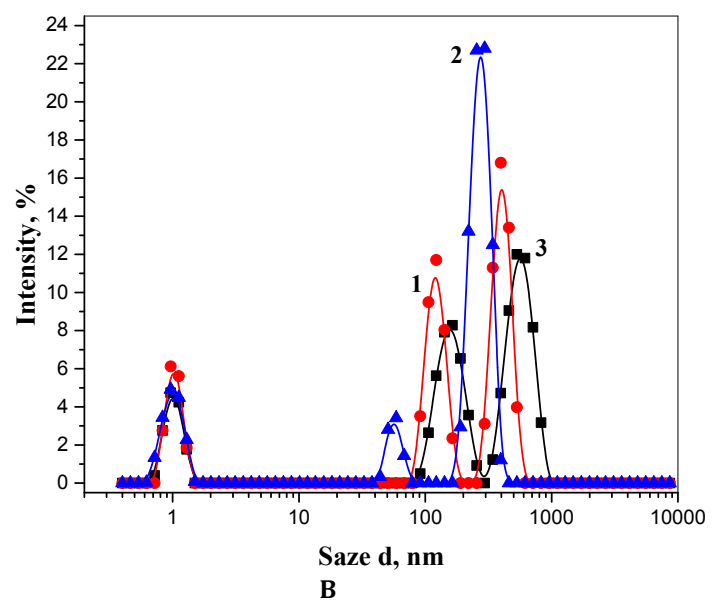

Fig. 10: Distribution of LW supramolecular complexes by size (DLS method data), A - before complex influence (temperature, moistened, gentle grinding); B-after the condition changes $(n \geq 15, p<0.05)$.1-Intact lactose; 2-FB placebo; 3-FB drug

As a result, the evidence of conformational mobility of the waterlactose supramolecular complex affecting its biological activity was obtained (fig. 11).

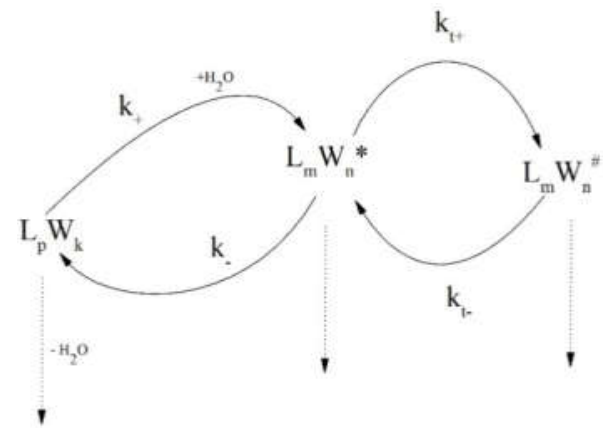

Fig. 11: Formation of the LW supramolecula complexes and reversible transitions between conformation states (L-Intact lactose, W-H2O, LmWn*-FB drug)

It is evident from the scheme that water molecules participate in the appearance of additional channels of inducible relaxation and contribute to the self-assembly of drug molecules into supramolecular complexes [54].

\section{DISCUSSION}

Lactose is one of the most frequently used pharmaceutical excipient for oral formulations. The technology of its saturation with API usually involves fluid bed apparatus. This process itself together with the complexity of modern drugs, make their challenging identification task. It is not only necessary to take into account the physical and chemical properties of API, but also the conditions of the realization their biological activity. One of the examples of such drugs is a drug investigated in our study. Using it, we developed an effective approach to investigate properties of biotechnological drugs coating lactose in fluid bed given the topicality of the issue presented by other researchers [55].

Changes in 2D-LS scattering time on sample surfaces, described by topological descriptors followed by Fourier Transformation, made it possible to clearly differentiate the intact lactose from fluidized samples by specific corridors in coordinates $d_{i}=F(t)$ [56]. The calculated $E_{a}$ values of cell biosensor death process in solutions of drugs coating lactose allow to characterize the biological activity of it's in the initial (by Ea increase) and activated state (by Ea decrease) after creation of intra-laboratory transmucosal conditions. A unique dimensional spectrum of water-lactose complexes in the nanoscale range has obtained by DLS. By LALLS we show the difference between samples in the distribution of LW complexes in size range from $1 \mu \mathrm{m}$ to $125 \mu \mathrm{m}$. Moreover, the results of our study confirmed that in spite of drug substance dilution (technological processing of the original substance under specific physical conditions) finally produced API contains nanosized structures that represents supramolecular complexes formed by antibodies and water molecule clusters [57]. Intra-laboratory transmucosal conditions proposed for in vitro testing of oral drugs should be used for improving the quality of analytical tests of complex biotechnological oral drugs.

\section{CONCLUSION}

The developed approach, including chemometrics, laser and Spirotox methods, can be used for qualitative analysis tasks as wel as for the analytical control of the fluidization process in cases where identifiable pharmaceutical substances are not distinguishable by traditional analytical methods.

\section{ACKNOWLEDGEMENT}

The publication has been prepared with the support of the "RUDN University Program 5-100". The authors thank Materia Medica Holding Company for the kind agreement to provide authors with the raw materials (antibodies to interferon-gamma and pharmaceutical excipients) for the study fulfillment.

\section{FUNDING}

Nil

\section{AUTHORS CONTRIBUTIONS}

All the authors have contributed equally.

\section{CONFLICT OF INTERESTS}

Drug substance (antibodies) and excipients were provided by Materia Medica Holding Company under the author's request. The company manufactures commercial drugs based on the provided substance. The authors declare that they personally and independently conducted research. The authors declare no other conflict of interest.

\section{REFERENSES}

1. Chauhan K, Solanki R, Sharma S. A review on fast dissolving tablet. Int J Appl Pharm 2018;10:1-7.

2. Mohs RC, Greig NH. Drug discovery and development: role of basic biological research. Alzheimers Dement (NY) 2017;3:651-7.

3. Durgapal S, Mukhopadhyay S, Goswami L. Preparation, characterization and evaluation of floating microparticles of ciprofloxacin. Int J Appl Pharm 2017;9:1-8. 
4. Bock CP, I Cho Y. Hydrodynamic and heat transfer study of dispersed fluids with submicron metallic oxide particles. Ex Heat Transfer 1998;11:151-70.

5. Sikalo S, Delalic N, Ganic EN. On the two-phase dispersed flow hydrodynamics and heat transfer investigations. Renewable Technol Sustainable Dev 2002;1:667-81.

6. Ommen JR, Manuel JV, Pfeffer RL. Fluidization of nanopowders: a review. J Nanopart 2012;43:737-48.

7. Cvetkovski CG, Reitsma S, Bolisetti T, Ting S. Heat transfer in a U-bend pipe: dean number versus reynolds number. Sustain Energy Techn 2015;11:148-58.

8. Filatov N, Belousov K, Bukatin A, Kukhtevich I, Evstrapov A The study of mixing of reagents within a droplet in various designs of microfluidic chip. J Phys: Conf Ser 2016;7:741-2.

9. Karimi A, Yazdi S, Ardekani AM. Hydrodynamic mechanisms of cell and particle trapping in microfuidics. Biomicrofuidics 2013;7:215-7.

10. Zhang S, Wang Y, Onck P, Toonder Jd. A concise review of microfluidic particle manipulation methods. Microfluid Nanofluid 2020;24:23-53.

11. Soleymani A, Kolehmainen E, Turunen I. Numerical and experimental investigations of liquid mixing in T-type micromixers. Chem Eng J 2008;135:S219-28.

12. Dey P, Saha SK, Chakraborty S. Confluence of channel dimensions and groove width dictates slippery hydrodynamics in grooved hydrophobic confinements. Microfluid Nanofluid 2020;24:232-46.

13. Monnard PA, Peter Walde. Current Ideas about prebiological compartmentalization. Life 2015;5:1239-13.

14. Epstein 0. The spatial homeostasis hypothesis. Symmetry 2018;10:103-17.

15. Slastnikova TA, Ulasov AV, Rosenkranz AA, Sobolev AS Targeted intracellular delivery of antibodies: the state of the art. Front Pharmacol 2018;24:9-12.

16. Chames P, Regenmortel MV, Weiss E, Baty D. Therapeutic antibodies: successes, limitations and hopes for the future. $\mathrm{Br}$ Pharmacol 2009;157:220-33.

17. Almeida H, Amaral MH, Lobao P. Drugs obtained by biotechnology processing Brazilian. J Pharm Sci 2011:47:199-208.

18. Mkrtumyan A, Romantsova T, Vorobiev S, Volkova A Vorokhobina N, Tarasov S, et al. Efficacy and safety of subetta add-on therapy in type 1 diabetes mellitus: the results of a multicenter, double-blind, placebo-controlled, randomized clinical trial. Diabetes Res Clin Pract 2018;142:1-9.

19. Smith JA, Judd J. Covid-19: vulnerability and the power of privilege in a pandemic. Health Promot J Austr 2020;20:1-3.

20. Odnovorov AI, Grebennikova TV, Pleteneva TV. Specific influenza therapy: current state and prospects (review). Razrab Regist Lek Sredstv 2020;9:83-91.

21. European Pharmacopoeia 7.0 V.1-2. Strasbourg: Council of Europe; 2010.

22. Zhang J, Wu CY, Pan $\mathrm{X}, \mathrm{Wu}$ C. On identification of critical material attributes for compression behaviour of pharmaceutical diluent. Materials 2017;10:845-61.

23. Carçabal P, Jockusch RA, Hünig I, Snoek LC, Kroemer RT, Davis $\mathrm{BG}$, et al. Hydrogen bonding and cooperativity in isolated and hydrated sugars: mannose, galactose, glucose, and lactose. J Am Chem Soc 2005;127:11414-25

24. Epshtein OI, Shtark MB, Kolyadko TM. US patent 8535664. Method of treating a pathological syndrome and a pharmaceutical agent. Inventors; 2013.

25. Don E, Farafonova O, Pokhil S, Barykina D, Nikiforova M, Shulga $D$, et al. Use of piezoelectric immunosensors for detection of interferon-gamma interaction with specific antibodies in the presence of released-active forms of antibodies to interferongamma. Sensors 2016;20:1-10.

26. Nasr A, Qushawy M, Swidan S. Spray dried lactose based proniosomes as stable provesicular drug delivery carriers screening, formulation, and physicochemical characterization. Int J Appl Pharm 2018;10:125-37.

27. Wang J, Shao Y, Yan X, Zhu J. Review of (gas)-liquid-solid circulating fluidized beds as biochemical and environmental reactors. Chem Eng J 2019;12:19-21.

28. Loh ZH, Dawn ZL, Chan LW, Liew CV, Heng PS. Spray granulation for drug formulation. Expert Opin Drug Delivery 2011;8:1645-61.
29. Wang J, Shao Y, Yan X, Zhu J. Review of (gas)-liquid-solid circulating fluidized beds as biochemical and environmental reactors. Chem Eng J 2019;12:19-51.

30. Jawecki CZ, Sawicki J. Toxicity of inorganic compounds in the spirotox test: a miniaturized version of the spirostomum ambiguum test. Arch Environ Contam Toxicol 1998;34:1-5.

31. Nałcz Jawecki G, Sawicki J. A comparison of sensitivity of spirotox biotest with standard toxicity tests. Arch Environ Contam Toxicol 2002;42:389-95.

32. Michel D. Simply conceiving the arrhenius law and absolute kinetic constants using the geometric distributionю phys. A Stat Mech Appl 2013;329:4258-64.

33. Peleg M, Normand MD, Corradini MG. The arrhenius equation revisited. Crit Rev Food Sci Nutr 2012;52:830-51.

34. Suhane S, Nerkar AG, Modi K, Sawant SD. 2D and 3D-qsar analysis of amino (3- $((3$, 5-difluoro-4-methyl-6phenoxypyridine-2-yl) oxy) phenyl) methaniminium derivatives as factor xa inhibitor. Int J Pharm Pharm Sci 2019;2:104-11.

35. Dastmalchia S, Hamzeh Mivehrouda M, Asadpour Zeynalic K Comparison of different 2D and 3D-QSAR methods on activity prediction of histamine $\mathrm{H} 3$ receptor antagonists. Iran J Pharm Res 2012;11:97-108.

36. Koldina AM, Uspenskaya EV, Borodin AA, Pleteneva TV Syroeshkin AV. Light scattering in research and quality control of deuterium depleted water for pharmaceutical application. Int J Appl Pharm 2019;11:271-8.

37. Syroeshkin A, Uspenskaya E, Pleteneva T, Morozova M Maksimova T, Koldina A, et al. Mechanochemical activation of pharmaceutical substances as a factor for modification of their physical, chemical and biological properties. Int J Appl Pharm 2019;11:118-23.

38. Kubicar L, Viliam V, Vlastimil B. Study of phase transitions by transient methods. Solid State Phenom 2008;138:3-28.

39. Quach NK, Yang WD, Chung ZJ, Tran HL. The influence of the activation temperature on the structural properties of the activated carbon xerogels and their electrochemical performance. Hindawi 2017;9:9-18.

40. Lewis WK, Gilliland ER, Bauer WC. Characteristics of fluidized particles. Ind Eng Chem 1949;41:1104-17.

41. Zhoua XR, Caoa Y, Zhanga Q, Tiana X, Dongb H, Chena L, et al. Self-assembly nanostructure controlled sustained release, activity and stability of peptide drugs. Int J Pharm 2017;528:723-31

42. Thombare M, Chavan P, Banka S. Solid-liquid circulating fluidized bed: a way forward. Rev Chem Eng 2017;35:1-44.

43. Grollman A. The vapor pressures of aqueous solutions with special reference to the problem of the state of water in biological fluids. J Gen Physiol 1931;14:661-83.

44. Wang J, Shao Y, Yan X, Zhu J. Review of (gas)-liquid-solid circulating fluidized beds as biochemical and environmental reactors. Chem Eng J 2019;12:1385-92.

45. Foroughi Dahr M, Mostoufi N, Sotudeh Gharebagh R, Chaouki J. Particle coating in fluidized beds. reference modue in chemistry, Molecular Sciences and Chemical Engineering; 2017;2:122-6.

46. Levitskaya OV, Syroeshkin AV, Pleteneva TV. Arrhenius kinetics as a bioactivity assessment criterion for drug substances and excipients. Pharm Chem J 2016;49:779-81.

47. Buonanno F, Guella G, Strim C, Ortenzi C. Chemical defence by mono-prenyl hydroquinone in a freshwater ciliate, spirostomum ambiguum. Hydrobiologia 2012;680:1-11.

48. Goncharuk VV, Syroeshkin AV, Zlatskiy IA. Quasichemical description of the cell death kinetics of cellular biosensor Spirostomum ambigua for testing the biological activity of aqueous solutions. J Water Chem Technol 2017;39:97-102.

49. Mauer J, Peltomäki M, Poblete S, Gomppe G, Fedosov D. Static and dynamic light scattering by red blood cells: a numerical study. PLoS One 2017;12:176-9.

50. Wang D, Phan N, Isely C, Bruene L, Bratlie KM. Effect of surface modification and macrophage phenotype on particle internalization. Biomacromolecules 2014;15:4102-10.

51. Hines RM, Khumnark M, Macphail B, Hines DJ. Administration of micronized caffeine using a novel oral delivery film results in 
rapid absorption and electroencephalogram suppression. Front Pharmacol 2019;10:983-8.

52. Post ST, Woutersen S, Bakker HJ. Quantum interference in the vibrational relaxation of the $\mathrm{O}-\mathrm{H}$ stretch overtone of liquid $\mathrm{H}_{2}$ O. J Physical Chem 2016;120:3441-9.

53. Medvedev ES, Osherov VI. Radiationless transitions in polyatomic molecules. Springer Ser Chem Phys 1995;57:196-9.

54. Kubicar L, Vretenar V, Bohac V. Study of phase transitions by transient methods. Solid State Phenom 2008;10:138, 3-28.
55. Sonar G, Rawat S. Optimization of pantoprazole enteric pellets coating process by QBD: effect of coating process variables on the intermediate quality of the product and scale up. Int J Pharm Pharm Sci 2015;7:80-7.

56. Raji K, Muthukumar V. Quantitative structure-activity relationships analysis of the anticonvulsant activity of erythrinine. Asian J Pharm Clin Res 2016;9:125-9.

57. Deore S, Shahi SR, Dabir P. Nanoparticle: as targeted drug delivery system for depression. Int J Curr Pharm Res 2016;8:7-11. 